\title{
Immunity to Polyomavirus BK Infection: Immune Monitoring to Regulate the Balance between Risk of BKV Nephropathy and Induction of Alloimmunity
}

\author{
Patrizia Comoli, ${ }^{1}$ Michela Cioni, ${ }^{2}$ Sabrina Basso, ${ }^{1}$ Chiara Gagliardone, ${ }^{1}$ Leonardo Potenza, ${ }^{3}$ \\ Enrico Verrina, ${ }^{4}$ Mario Luppi, ${ }^{3}$ Marco Zecca, ${ }^{1}$ Gian Marco Ghiggeri, ${ }^{4}$ and Fabrizio Ginevri ${ }^{4}$ \\ ${ }^{1}$ Pediatric Hematology/Oncology, Fondazione IRCCS Policlinico San Matteo, 27100 Pavia, Italy \\ ${ }^{2}$ Fondazione Malattie Renali del Bambino, Istituto G. Gaslini, 16147 Genoa, Italy \\ ${ }^{3}$ Section of Hematology, Department of Medical and Surgical Sciences, University of Modena and Reggio Emilia, 41124 Modena, Italy \\ ${ }^{4}$ Pediatric Nephrology, Istituto G. Gaslini, 16147 Genoa, Italy \\ Correspondence should be addressed to Fabrizio Ginevri; fabrizioginevri@ospedale-gaslini.ge.it
}

Received 23 February 2013; Revised 9 July 2013; Accepted 17 July 2013

Academic Editor: Aron Chakera

Copyright (C) 2013 Patrizia Comoli et al. This is an open access article distributed under the Creative Commons Attribution License, which permits unrestricted use, distribution, and reproduction in any medium, provided the original work is properly cited.

\begin{abstract}
Polyomavirus BK-associated nephropathy (PyVAN) is the main infectious cause of allograft damage after kidney transplantation. A number of studies revealed an association between the presence of BKV-specific cellular immunity and BK viral clearance, with patients failing to recover specific T cells progressing to PyVAN. Evolution to allograft dysfunction can be prevented by restoration of BKV-specific immunity through a stepwise reduction of maintenance immunosuppressive drugs. Prospective monitoring of BK viral load and specific immunity, together with B-cell alloimmune surveillance, may allow a targeted modification/reduction of immunosuppression, with the aim of obtaining viral clearance while preventing graft injury due to deposition of de novo donorspecific HLA antibodies and late/chronic antibody-mediated allograft injury. Innovative, immune-based therapies may further contribute to BKV infection prevention and control.
\end{abstract}

\section{Introduction}

The morbidity and mortality of viral infections are significantly increasing in transplant patients. The reason resides in the severe impairment in immune surveillance caused by the development of potent induction and maintenance immunosuppressive protocols, which has led to a significant amelioration of graft outcome but, on the other hand, has weakened protective immune functions against pathogens [1]. Systematic immune control is needed in order to restrict the rate and level of latent virus reactivation since, by definition, clearance from the host cannot be obtained for such viruses, regardless of the antiviral treatment.

Polyomavirus BK (BKV), first isolated in the 1970s, is a double-stranded DNA virus with a genome structure consisting of the early nonstructural genes encoding large $\mathrm{T}$ and small $t$ antigens, the late genes encoding the capsid proteins
(VP1, VP2, and VP3) and the agnoprotein and a noncoding control region (NCCR) harboring viral promoters and the origin of replication [2]. BKV seroprevalence exceeds $90 \%$ in the adult population worldwide, but the infection does not cause illness in healthy individuals [3]. Prevalence and level of BKV replication in urine, occasionally observed in healthy individuals [4], may increase with pregnancy, kidney disease, and immunodeficiency status including hematopoietic stem cell and renal transplantation [2]. In the latter setting, BKV has emerged in the last 15 years as the most challenging infectious cause of renal allograft dysfunction and graft loss [5]. BKV-related nephropathy (PyVAN) was initially reported to cause graft loss in $10 \%$ to $>80 \%$ of cases [5-8], but implementation of BKV monitoring strategies after transplantation and prompt/preemptive therapeutic intervention had a positive impact on graft outcome $[6,9,10]$. 
In association with viral load determination, quantification of the specific immune response has gained consideration as a useful tool in the management of viral infections in the immunocompromised host. In detail, viral immunity monitoring has allowed the characterization of subgroups of patients at high risk for disease development [11] and assessment of response to antiviral therapy [12]. In addition, as control of infection depends on the restoration of a protective immune response, characterization of specific viral immunity has facilitated development of recombinant or cellular vaccines [13-15].

Here, we will review available evidence on BKV-specific immune responses, suggest an immunological monitoring approach to the management of $\mathrm{BKV}$ reactivation and PyVAN, and discuss possible future immune-based therapeutic options.

\section{Diagnosis and Monitoring of BK Infection}

PyVAN diagnosis is made by renal biopsy, with evidence of polyomavirus cytopathic changes and interstitial nephritis $[5,9,10,16]$, but the focal nature of the disease and the possible overlap with other pathologies that complicate the posttransplant course could make difficult an early diagnosis.

PyVAN represents a complication linked to high-rate virus replication in the grafted kidney $[2,17]$. Thus, monitoring of BK viruria, generally by urine cytology or quantitative PCR for viral DNA, and monitoring of BK viremia, by quantitative PCR, allow the identification of patients at risk of developing PyVAN $[5,9,10]$. Urine and plasma seem to be separate replication compartments, with plasma being directly linked to graft replication [18]. Consequently, sustained detection of BKV replication, assessed as plasma loads by quantitative PCR, is the most predictive assay for the presence of "presumptive" PyVAN [2, 5, 17], and for this reason, it is recommended by current guidelines as the best assay to guide preemptive interventions [5, 9, 10, 19-21].

In association with viral molecular monitoring, analysis of specific immune responses could become instrumental in assisting the surveillance and treatment of kidney recipients with BKV replication and PyVAN $[22,23]$. However, in order to reach this aim, assessment of the most cost-effective immune monitoring protocol together with development and standardization of "high throughput" assays is needed [24].

\section{Immune Responses in Patients with BK Infection and Disease}

To introduce a proposal for a protocol of specific immune monitoring to be employed in patients with BKV replication or PyVAN, we shall give a preliminary overview of humoral and cellular immunity in patients with active BKV infection and disease.

3.1. Innate Immune Responses. The host immune response is of central importance in limiting primary viral infection and in controlling the virus carrier state. In general, the first line of defense against infection, prior to increase in antibody titers and epitope-specific HLA-restricted T-cell populations, is under control of innate responses and nonspecific cytotoxic cells (natural killer cells, lymphokine-activated cells, and MHC-unrestricted $\gamma \delta^{+}$T-lymphocytes). One study demonstrated an association between lack of the HLA-C7 allele and sustained BK viremia [25], indirectly suggesting a role for inhibitory and activating killer-cell immunoglobulin-like receptors (KIRs) in the control of BKV infection. However, KIR genotyping studies, which had demonstrated a role for activating KIRs in the control of CMV infection in both hematopoietic stem cell and kidney transplantation [26, 27], ruled out an effect of KIR genotype on the rate of BKV reactivation [27].

Innate immunity may also have a detrimental role in $\mathrm{BKV}$-related disease. A recent report demonstrated in biopsies with PyVAN that the activation of innate immune defense mechanisms, especially via TLR3, is implicated in the antiviral and inflammatory response [28].

3.2. Humoral Immune Responses. Humoral immunity still has a controversial role in the regulation of BKV activity. BKV-specific antibodies are present in $82 \%$ of individuals [4]. Studies conducted in pediatric kidney transplant recipients have shown that BKV seronegativity correlates with a higher risk of BKV replication and PyVAN $[29,30]$. However, clinical observations indicate that having experienced a humoral response does not give full protection from post-transplant reactivation of viral replication and development of polyomavirus-related disease $[5,20]$.

In cohorts of kidney transplant recipients experiencing high-levels of viruria or viremia, compared to patients without active viral replication, the course of BKV-specific antibody responses has been shown to follow the level and duration of BKV replication [20, 25, 31, 32].

3.3. Cellular Immune Responses. The coincidence of PyVAN with the widespread clinical application of potent triple immunosuppressive regimens suggests a role for marked cellular immunodeficiency in disease progression. Likewise, one study showed that pretransplant dendritic cell deficiency, leading to diminished antigen presentation and $\mathrm{T}$ cell activation, correlated with a high risk of posttransplant $\mathrm{BKV}$ viremia and progression to PyVAN [33]. Early studies demonstrated that control of BKV replication and PyVAN in kidney recipients correlated with emergence of BKV-specific cellular immune responses [34, 35]. Moreover, a longitudinal analysis showed that kidney recipients with $\mathrm{BKV}$ reactivation had undetectable levels of BKV-specific IFN- $\gamma$ secreting cells. Upon immunosuppression reduction, while BKV loads in plasma and urine declined, an increase in the frequency of virus-specific $\mathrm{T}$ cells was observed, which coincided with reduction of serum creatinine levels, an index of allograft function stabilization [20]. A recent study confirmed that patients with self-limited $\mathrm{BKV}$ reactivation were those who rapidly developed $\mathrm{BKV}$-specific $\mathrm{T}$ cells without therapeutic interventions [36].

The cellular response pattern to BKV antigens has been an object of study. Results obtained in healthy individuals and in kidney transplant recipients revealed responses to BKV large T, small t, VP1, VP2, and VP3 proteins, but no 
immunodominant antigen was identified [37, 38]. Analyzing cases of resolved PyVAN/past BK viremia or patients with transient/no BKV infection, two independent groups found higher frequencies of IFN- $\gamma$ producing $\mathrm{T}$ cells directed to viral capsid antigens, respectively, VP1 and VP3, in the former group $[20,35,39,40]$. In conclusion, although recent studies confirmed that lymphocytes directed to all five BKV proteins are potentially inducible $[15,38-40]$, the magnitude of the capsid protein-specific pool is highest. Conversely, Leuenberger et al. demonstrated that agnoprotein is immunologically ignored [41]. Cioni et al. have recently investigated whether agnoprotein might contribute to BKV immune evasion by interfering with HLA surface expression or peptide presentation and found that no HLA-ABC or DR downregulation, as well as no interference with peptide-dependent cytotoxicity, was mediated by the agnoprotein [42].

Although data are available on the distribution and immunodominance of responses to BKV proteins, there is limited evidence on their respective role in the containment of BKV replication and progression to disease. In this regard, Comoli et al. [43] have shown in a prospective study that the presence of large $\mathrm{T}$ antigen-specific, but not VP1-specific, cytotoxic $\mathrm{T}$ cells at an early time after transplantation protects from the risk of $\mathrm{BK}$ viruria and that in patients with viruria, the emergence of BKV LT antigen-specific immunity is associated with protection from development of BK viremia.

Though several studies focused on BKV-specific cell immunity, it remains unclear whether BKV responses are mediated preferentially by $\mathrm{CD} 4^{+}$or $\mathrm{CD}^{+}$T-lymphocytes, and in particular which subset plays a protective role in the control of the infection $[20,35,38-40]$. It was shown that in kidney transplant patients with active or past BKV replication VP1-specific IFN- $\gamma$-producing $\mathrm{T}$ cells were preferentially $\mathrm{CD}^{+}$, whereas the $\mathrm{CD} 8^{+}$population was predominantly large $\mathrm{T}$ specific [35]. In agreement with these observations, it was shown that BKV seropositive donors mount a powerful CTL response towards epitopes encompassed by a highly phylogenetically conserved region of the LTag implicated in viral replicative activity and in the p53-mediated control of the cell cycle of host cells [44], and BKV-directed cytotoxic activity in kidney recipients after viral clearance was mostly directed against LT antigen [20]. On the other hand, the magnitude of memory multifunctional $\mathrm{CD} 4^{+} \mathrm{T}$ cells was found to correlate with the severity of the previous $\mathrm{BKV}$ infection [40], and a higher frequency of BKV large T-specific CD4 ${ }^{+}$ cells characterized by a cytotoxic profile (secretion of TNF$\alpha$, IFN- $\gamma$, and presence of Granzyme A and B) was shown in healthy individuals [38]. Although this issue needs to be further investigated, there is preliminary evidence suggesting that $\mathrm{CD} 4^{+} \mathrm{T}$-lymphocytes could play an essential role not only in providing helper functions but also as effectors able to exert direct control of virus replication [29].

\section{Management of BKV Reactivation, PyVAN, and the Risk of Antibody-Mediated Graft Damage: The Role of Immune Monitoring}

No specific antiviral therapy has, so far, proven effective in containing PyVAN and preventing allograft damage $[45,46]$.
However, a number of studies have shown that progression to PyVAN can be safely prevented if BKV viremia is used to guide therapeutic intervention $[17,19,20]$.

BKV replication is generally an early event after allografting, and therapeutic reduction of immunosuppressive agents in this crucial phase of transplantation may induce acute rejection episodes, or, worse, affect long-term allograft outcome. Indeed, in a study of PyVAN surveillance and preemptive therapy, for adult kidney recipients with BK viremia treated with concomitant reduction of calcineurin inhibitors (CI) and mycophenolate mofetil (MMF), an acute rejection incidence of $13 \%$ was observed after modulation of immunosuppression [21]. Moreover, in the cohort treated with stepwise reduction of immunosuppression by Brennan et al. [19], despite the low acute rejection rate, a significantly worse graft outcome for BK viremic patients was observed at long-term followup [47].

Late/chronic active antibody mediated rejection (CAMR) has emerged as an important cause of late kidney transplant failure [48]. Lately, development of de novo donor-specific HLA antibodies (DSA) was found to be associated with CAMR and poor graft outcome in adult and pediatric cohorts of kidney recipients at low immunological risk $[49,50]$. In a low-risk pediatric population on conventional CNI-based triple drug regimen, development of de novo DSA occurs in almost a fourth of the patients [50]. It has been hypothesized that a potentially self-limiting and transient broad pan-B cell activation, due to non-specific stimuli [51], or to low-level allo-specific T-cell help to B-cells promoted by the loss of induction therapy effect and by protocol decrease in maintenance immunosuppression, may, under particular clinical conditions, such as molecular mimicry elicited by viral reactivation [52], be amplified and lead to the emergence of DSA [50]. In this scenario, BKV reactivation could represent both a trigger for B cell activation, and, through specific therapeutic reduction of immunosuppression, sustainment of DSA formation.

In the setting thus delineated, detection of BKV-specific $\mathrm{T}$ cells by immune monitoring represents a unique tool to allow for a cautious modulation of immune suppression, with the ultimate goal of controlling viral reactivation while maintaining adequate immune suppression to protect the graft [24]. Indeed, we have evidence that as soon as virus-specific Tcell responses appear, the patient acquires protection from PyVAN progression [20]. Thus, we propose a combined immune surveillance approach: through DSA monitoring, we could identify viremic patients at potential risk of CAMR secondary to immunosuppression reduction, while $\mathrm{BKV}$ cellular immunity monitoring could tell us in which of these patients we may safely consider restoring part of the preinfection maintenance immunosuppression.

\section{A Launch into the Future: Innovative Immune-Based Therapeutic Strategies to Control Polyomavirus Infection and Prevent Related Disease}

As several reports have demonstrated that an efficient $\mathrm{BKV}$-specific T-cell response is crucial for control of viral 
replication and prevention of progression to PyVAN, the development of alternative therapeutic approaches aiming to restore an effective viral-specific immune response, is an attractive alternative to current treatment options $[15,20,34-$ 40].

Antiviral cell therapy strategies, at first successfully employed in the setting of hematopoietic stem cell transplantation $[53,54]$, have subsequently been transferred to the setting of organ transplantation $[55,56]$. Our group described a method for the generation of BKV-specific CTLs from BKVseropositive healthy donors and kidney transplant patients, based on the stimulation of PBMC with dendritic cells pulsed with inactivated BKV, in the presence of IL-7 and IL-12 [57]. As result, it was possible to obtain BKV-specific $\mathrm{T}$ cells with cytotoxic activity. In particular, a high frequency of $\mathrm{CD}^{+} / \mathrm{TCR} \gamma \delta^{+}$cells was observed, displaying an MHCunrestricted cytotoxicity and suggesting a protective role in the control of the virus from the graft [9].

The use of BKV protein peptide mixtures as the antigen stimulus would permit good manufacturing practice (GMP) generation of T-cell lines with multiple specificities to be used for patients of any HLA type. Recently, Blyth et al. [14] generated BKV-specific $\mathrm{T}$ cells for possible use in adoptive cell transfer by antigenic stimulation with 15 mer peptide pools derived from VP-1, VP-2, VP-3, small $t$, and large T antigens. As the frequency of $\mathrm{T}$ cells specific for BKV was rather low when compared to other persistent viruses, $15 \mathrm{mer}$ peptides may not be an optimal antigen for T-cell generation. Unfortunately, HLA-restricted T-cell response to BKV is so far poorly characterized and only few VP-1 and large T antigen epitopes have been defined, with most of the described epitopes being HLA A* 02 restricted [38, 44, 58-61]. Recently, a large $\mathrm{T}$ antigen-derived peptide has been described that seems to elicit a $\mathrm{CD} 4^{+}$T-cell response across different HLA types [62].

No clinical trial has so far been published on adoptive BKV-specific T-cell transfer. However, our group was successful in treating an HSCT recipient affected by progressive multifocal leukoencephalopathy with polyomavirus JC-specific T cells obtained by stimulating PBMCs from the HSCT donor with a pool of 15 mer peptides spanning the whole sequence of JCV VP-1 and the large T antigen [63]. A similar strategy could be employed in case of JC-mediated PyVAN [64] and be translated to the treatment of BK PyVAN.

Finding immunodominant peptides would be of interest also in the context of vaccine development. As peptide vaccination is generally a poor inducer of cellular immunity, the use of carrier adjuvants may be necessary. Virus-like particles (VLPs) are optimal carrieres for antigen delivery. Murine polyomavirus VLPs were tested in mice and found to induce a strong humoral and cellular immune response [65]. An infectious recombinant $\mathrm{BK}$ virus, in which the large $\mathrm{T}$ sequence could be modified to avoid any safety implication related to the potential tumorigenicity of large $\mathrm{T}$ antigen, was recently proposed as an alternative strategy for vaccination in the context of BKV [66].

\section{Conclusions}

Successful clearance of BK viremia and prevention of PyVAN after kidney transplantation rely on the efficiency of the immune system and, more precisely, specific T-cell immunity. Reduction of maintenance immunosuppression is able to restore protective immunity, but recent evidence indicates how immune suppression modulation needs to be carefully balanced against the risk of inducing de novo DSA and CAMR.

Combined monitoring of DSA and BKV-specific T cells could provide an easy and safe tool for the therapeutic management of kidney recipients developing BKV reactivation. Novel immune-based strategies, including vaccination and cell therapy, might further contribute to the prevention of $\mathrm{BKV}$ infection and related disease.

\section{Conflict of Interests}

The authors have no conflict of interests to declare.

\section{Acknowledgments}

This study was supported by Grants from the Ministry of Health, Ricerca Finalizzata (Patrizia Comoli, Michela Cioni, Leonardo Potenza, Marco Zecca, Gian Marco Ghiggeri); Fondazione IRCCS Policlinico S. Matteo, Pavia (Marco Zecca); Associazione Italiana per la Ricerca sul Cancro (AIRC), Milan, Italy (Patrizia Comoli and Mario Luppi); Regione Lombardia, Progetto Trapianto (Patrizia Comoli, Fabrizio Ginevri); the Associazione Italiana Lotta alle Leucemie, Linfoma e Mieloma (AIL), Sezione "Luciano Pavarotti" Modena-ONLUS (Leonardo Potenza); Programma di Ricerca Regione-Universitá (PRU 2007-2009) Emilia Romagna (Mario Luppi); the European Commission's FP6 Life-Science-Health Programme (INCA project; LSHC-CT2005-018704) (Mario Luppi); "Cinque per mille IRPEFFinanziamento della Ricerca Sanitaria" Istituto G. Gaslini, to Fabrizio Ginevri and Gian Marco Ghiggeri; Istituto G. Gaslini, progetti Ricerca Corrente, Ministero della Salute (contributo per la ricerca intramurale) to Fabrizio Ginevri and Gian Marco Ghiggeri; grant from Fondazione La Nuova Speranza Onlus to Fabrizio Ginevri, Patrizia Comoli, and Gian Marco Ghiggeri. Fabrizio Ginevri and Michela Cioni are recipients of Grants from the Fondazione Malattie Renali del Bambino.

\section{References}

[1] J. A. Fishman and R. H. Rubin, "Infection in organ-transplant recipients," New England Journal of Medicine, vol. 338, no. 24, pp. 1741-1751, 1998.

[2] H. H. Hirsch and J. Steiger, "Polyomavirus BK," Lancet Infectious Diseases, vol. 3, no. 10, pp. 611-623, 2003.

[3] H. H. Hirsch, "BK virus: opportunity makes a pathogen," Clinical Infectious Diseases, vol. 41, no. 3, pp. 354-360, 2005.

[4] A. Egli, L. Infanti, A. Dumoulin et al., "Prevalence of polyomavirus BK and JC infection and replication in 400 healthy blood donors," Journal of Infectious Diseases, vol. 199, no. 6, pp. 837-846, 2009. 
[5] H. H. Hirsch, D. C. Brennan, C. B. Drachenberg et al., "Polyomavirus-associated nephropathy in renal transplantation: interdisciplinary analyses and recommendations," Transplantation, vol. 79, no. 10, pp. 1277-1286, 2005.

[6] B. Vasudev, S. Hariharan, S. A. Hussain, Y.-R. Zhu, B. A. Bresnahan, and E. P. Cohen, "BK virus nephritis: risk factors, timing, and outcome in renal transplant recipients," Kidney International, vol. 68, no. 4, pp. 1834-1839, 2005.

[7] P. Comoli and F. Ginevri, "Monitoring and managing viral infections in pediatric renal transplant recipients," Pediatric Nephrology, vol. 27, pp. 705-717, 2011.

[8] P. D. Acott and H. H. Hirsch, "BK virus infection, replication, and diseases in pediatric kidney transplantation," Pediatric Nephrology, vol. 22, no. 9, pp. 1243-1250, 2007.

[9] "Kidney Disease Improving Global Outcomes (KDIGO) guidelines," American Journal of Transplantation, vol. 9, supplement 3, pp. S112-S124, 2009.

[10] H. Hirsch and P. Randhawa, "AST infectious diseases community of practice. BK polyomavirus in solid organ transplant recipients," American Journal of Transplantation, vol. 13, pp. 179188, 2013.

[11] F. Smets, D. Latinne, H. Bazin et al., "Ratio between EpsteinBarr viral load and anti-Epstein-Barr virus specific T-cell response as a predictive marker of posttransplant lymphoproliferative disease," Transplantation, vol. 73, no. 10, pp. 1603-1610, 2002.

[12] P. Comoli, R. Maccario, F. Locatelli et al., "Treatment of EBVrelated post-renal transplant lymphoproliferative disease with a tailored regimen including EBV-specific T cells," American Journal of Transplantation, vol. 5, no. 6, pp. 1415-1422, 2005.

[13] P. Comoli, F. Locatelli, F. Ginevri, and R. Maccario, "Cellular immunotherapy for viral infections in solid organ transplantation," Current Opinion in Organ Transplantation, vol. 7, pp. 314$319,2002$.

[14] E. Blyth, L. Clancy, R. Simms et al., "BK virus-specific T cells for use in cellular therapy show specificity to multiple antigens and polyfunctional cytokine responses," Transplantation, vol. 92, no. 10, pp. 1077-1084, 2011.

[15] A. Chakera, S. Bennett, S. Lawrence et al., "Antigen-specific T cell responses to BK polyomavirus antigens identify functional anti-viral immunity and may help to guide immunosuppression following renal transplantation," Clinical and Experimental Immunology, vol. 165, no. 3, pp. 401-409, 2011.

[16] C. B. Drachenberg, J. C. Papadimitriou, H. H. Hirsch et al., "Histological patterns of polyomavirus nephropathy: correlation with graft outcome and viral load," American Journal of Transplantation, vol. 4, no. 12, pp. 2082-2092, 2004.

[17] H. H. Hirsch, W. Knowles, M. Dickenmann et al., "Prospective study of polyomavirus type BK replication and nephropathy in renal-transplant recipients," New England Journal of Medicine, vol. 347, no. 7, pp. 488-496, 2002.

[18] G. A. Funk, J. Steiger, and H. H. Hirsch, "Rapid dynamics of polyomavirus type BK in renal transplant recipients," Journal of Infectious Diseases, vol. 193, no. 1, pp. 80-87, 2006.

[19] D. C. Brennan, I. Agha, D. L. Bohl et al., "Incidence of BK with tacrolimus versus cyclosporine and impact of preemptive immunosuppression reduction," American Journal of Transplantation, vol. 5, pp. 582-594, 2005.

[20] F. Ginevri, A. Azzi, H. H. Hirsch et al., "Prospective monitoring of polyomavirus BK replication and impact of pre-emptive intervention in pediatric kidney recipients," American Journal of Transplantation, vol. 7, no. 12, pp. 2727-2735, 2007.
[21] E. R. Saad, B. A. Bresnahan, E. P. Cohen et al., "Successful treatment of BK viremia using reduction in immunosuppression without antiviral therapy," Transplantation, vol. 85, no. 6, pp. 850-854, 2008.

[22] P. Comoli, S. Binggeli, F. Ginevri, and H. H. Hirsch, "Polyomavirus-associated nephropathy: update on BK virus-specific immunity," Transplant Infectious Disease, vol. 8, no. 2, pp. 86-94, 2006.

[23] N. Babel, H.-D. Volk, and P. Reinke, "BK polyomavirus infection and nephropathy: the virus-immune system interplay," Nature Reviews Nephrology, vol. 7, no. 7, pp. 399-406, 2011.

[24] P. Comoli, H. H. Hirsch, and F. Ginevri, "Cellular immune responses to BK virus," Current Opinion in Organ Transplantation, vol. 13, no. 6, pp. 569-574, 2008.

[25] D. L. Bohl, G. A. Storch, C. Ryschkewitsch et al., "Donor origin of BK virus in renal transplantation and role of HLA C7 in susceptibility to sustained BK viremia," American Journal of Transplantation, vol. 5, no. 9, pp. 2213-2221, 2005.

[26] M. Cook, D. Briggs, C. Craddock et al., "Donor KIR genotype has a major influence on the rate of cytomegalovirus reactivation following T-cell replete stem cell transplantation," Blood, vol. 107, no. 3, pp. 1230-1232, 2006.

[27] M. Stern, H. Elsässer, G. Hönger, J. Steiger, S. Schaub, and C. Hess, "The number of activating KIR genes inversely correlates with the rate of CMV infection/reactivation in kidney transplant recipients," American Journal of Transplantation, vol. 8, no. 6, pp. 1312-1317, 2008.

[28] A. Ribeiro, M. Wörnle, N. Motamedi et al., "Activation of innate immune defense mechanisms contributes to polyomavirus BKassociated Nephropathy," Kidney International, vol. 81, pp. 100111, 2012.

[29] F. Ginevri, R. de Santis, P. Comoli et al., "Polyomavirus BK infection in pediatric kidney-allograft recipients: a singlecenter analysis of incidence, risk factors, and novel therapeutic approaches," Transplantation, vol. 75, no. 8, pp. 1266-1270, 2003.

[30] J. M. Smith, R. A. McDonald, L. S. Finn, P. J. Healey, C. L. Davis, and A. P. Limaye, "Polyomavirus nephropathy in pediatric kidney transplant recipients," American Journal of Transplantation, vol. 4, no. 12, pp. 2109-2117, 2004.

[31] D. L. Bohl, D. C. Brennan, C. Ryschkewitsch, M. GaudreaultKeener, E. O. Major, and G. A. Storch, "BK virus antibody titers and intensity of infections after renal transplantation," Journal of Clinical Virology, vol. 43, no. 2, pp. 184-189, 2008.

[32] S. Hariharan, E. P. Cohen, B. Vasudev et al., "BK virus-specific antibodies and BKV DNA in renal transplant recipients with BKV nephritis," American Journal of Transplantation, vol. 5, no. 11, pp. 2719-2724, 2005.

[33] K. L. Womer, Y. Huang, H. Herren et al., "Dendritic cell deficiency associated with development of BK viremia and nephropathy in renal transplant recipients," Transplantation, vol. 89, no. 1, pp. 115-123, 2010.

[34] P. Comoli, A. Azzi, R. Maccario et al., "Polyomavirus BKspecific immunity after kidney transplantation," Transplantation, vol. 78, no. 8, pp. 1229-1232, 2004.

[35] S. Binggeli, A. Egli, S. Schaub et al., "Polyomavirus BK-specific cellular immune response to VP1 and large T-antigen in kidney transplant recipients," American Journal of Transplantation, vol. 7, no. 5, pp. 1131-1139, 2007.

[36] T. Schachtner, K. Müller, M. Stein et al., "BK virus-specific immunity kinetics: a predictor of recovery from polyomavirus BK-associated nephropathy," American Journal of Transplantation, vol. 11, no. 11, pp. 2443-2452, 2011. 
[37] D. Tong, J. Miller, K. Kokko et al., "Healthy individuals generate a predominantly CD4 cell reponse against polyomavirus BK," American Journal of Transplantation, vol. 5, supplement 11, article 452, 2005.

[38] W. Zhou, M. Sharma, J. Martinez et al., "Functional characterization of BK virus-specific CD4+ T cells with cytotoxic potential in seropositive adults," Viral Immunology, vol. 20, no. 3, pp. 379-388, 2007.

[39] H. Trydzenskaya, A. Sattler, K. Müller et al., "Novel approach for improved assessment of phenotypic and functional characteristics of BKV-specific T-cell immunity," Transplantation, vol. 92, no. 11, pp. 1269-1277, 2011.

[40] K. Mueller, T. Schachtner, A. Sattler et al., "BK-VP3 as a new target of cellular immunity in BK virus infection," Transplantation, vol. 91, no. 1, pp. 100-107, 2011.

[41] D. Leuenberger, P. A. Andresen, R. Gosert et al., "Human polyomavirus type 1 (BK virus) agnoprotein is abundantly expressed but immunologically ignored," Clinical and Vaccine Immunology, vol. 14, no. 8, pp. 959-968, 2007.

[42] M. Cioni, C. Mittelholzer, M. Wernli, and H. H. Hirsch, "Comparing effects of BK virus agnoprotein and Herpes Simplex1 ICP47 on MHC-I and MHC-II expression," Clinical and Developmental Immunology, vol. 2013, Article ID 626823, 10 pages, 2013.

[43] P. Comoli, S. Basso, H. Hirsch et al., "Humoral and cellular immunity to polyomavirus BK large T and VP1 antigens after pediatric kidney transplantation," American Journal of Transplantation, vol. 8, supplement 2, article 283, 2008.

[44] M. Provenzano, L. Bracci, S. Wyler et al., "Characterization of highly frequent epitope-specific CD45RA+/CCR7+/- T lymphocyte responses against p53-binding domains of the human polyomavirus BK large tumor antigen in HLA-A $* 0201+\mathrm{BKV}-$ seropositive donors," Journal of Translational Medicine, vol. 4, article 47, 2006.

[45] V. R. Dharnidharka, W. S. Cherikh, and K. C. Abbott, "An OPTN analysis of national registry data on treatment of BK virus allograft nephropathy in the United States," Transplantation, vol. 87, no. 7, pp. 1019-1026, 2009.

[46] J. D. Schold, S. Rehman, L. K. Kayler, J. Magliocca, T. R. Srinivas, and H.-U. Meier-Kriesche, "Treatment for BK virus: incidence, risk factors and outcomes for kidney transplant recipients in the United States," Transplant International, vol. 22, no. 6, pp. 626634, 2009.

[47] K. L. Hardinger, M. J. Koch, D. J. Bohl, G. A. Storch, and D. C. Brennan, "BK-virus and the impact of pre-emptive immunosuppression reduction: 5-year results," American Journal of Transplantation, vol. 10, no. 2, pp. 407-415, 2010.

[48] R. S. Gaston, J. M. Cecka, B. L. Kasiske et al., "Evidence for antibody-mediated injury as a Major determinant of late kidney allograft failure," Transplantation, vol. 90, no. 1, pp. 68-74, 2010.

[49] C. Wiebe, I. W. Gibson, T. D. Blydt-Hansen et al., "Evolution and clinical pathologic correlations of de novo donor-specific HLA antibody post kidney transplant," American Journal of Transplantation, vol. 12, no. 5, pp. 1157-1167, 2012.

[50] F. Ginevri, A. Nocera, P. Comoli et al., "Post-transplant de novo donor-specific HLA antibodies identify pediatric kidney recipients at risk for late antibody mediated rejection," American Journal of Transplantation, vol. 12, pp. 3355-3362, 2012.

[51] N. L. Bernasconi, E. Traggiai, and A. Lanzavecchia, "Maintenance of serological memory by polyclonal activation of human memory B cells," Science, vol. 298, no. 5601, pp. 2199-2202, 2002.
[52] G. Pietra, C. Romagnani, P. Mazzarino et al., "HLA-E-restricted recognition of cytomegalovirus-derived peptides by human CD8+ cytolytic T lymphocytes," Proceedings of the National Academy of Sciences of the United States of America, vol. 100, no. 19, pp. 10896-10901, 2003.

[53] S. R. Riddell, K. S. Watanabe, J. M. Goodrich, C. R. Li, M. E. Agha, and P. D. Greenberg, "Restoration of viral immunity in immunodeficient humans by the adoptive transfer of $\mathrm{T}$ cell clones," Science, vol. 257, no. 5067, pp. 238-241, 1992.

[54] C. M. Rooney, C. A. Smith, C. Y. C. Ng et al., "Use of genemodified virus-specific T lymphocytes to control Epstein-Barrvirus-related lymphoproliferation," The Lancet, vol. 345, no. 8941, pp. 9-13, 1995.

[55] P. Comoli, M. Labirio, S. Basso et al., "Infusion of autologous Epstein-Barr virus (EBV)-specific cytotoxic T cells for prevention of EBV-related lymphoproliferative disorder in solid organ transplant recipients with evidence of active virus replication," Blood, vol. 99, no. 7, pp. 2592-2598, 2002.

[56] P. Comoli, R. Maccario, F. Locatelli et al., "Treatment of EBVrelated post-renal transplant lymphoproliferative disease with a tailored regimen including EBV-specific T cells," American Journal of Transplantation, vol. 5, no. 6, pp. 1415-1422, 2005.

[57] P. Comoli, S. Basso, A. Azzi et al., "Dendritic cells pulsed with polyomavirus $\mathrm{BK}$ antigen induce ex vivo polyoma $\mathrm{BK}$ virusspecific cytotoxic T-cell lines in seropositive healthy individuals and renal transplant recipients," Journal of the American Society of Nephrology, vol. 14, no. 12, pp. 3197-3204, 2003.

[58] P. S. Randhawa, I. Popescu, C. Macedo et al., "Detection of CD8+ T cells sensitized to BK virus large T antigen in healthy volunteers and kidney transplant recipients," Human Immunology, vol. 67, no. 4-5, pp. 298-302, 2006.

[59] P. M. Sharma, G. Gupta, A. Vats, R. Shapiro, and P. Randhawa, "Phylogenetic analysis of polyomavirus BK sequences," Journal of Virology, vol. 80, no. 18, pp. 8869-8879, 2006.

[60] J. Li, J. Melenhorst, N. Hensel et al., "T-cell responses to peptide fragments of the $\mathrm{BK}$ virus $\mathrm{T}$ antigen: implications for crossreactivity of immune response to JC virus," Journal of General Virology, vol. 87, no. 10, pp. 2951-2960, 2006.

[61] B. Ramaswami, I. Popescu, C. Macedo et al., "HLA-A01-, -A03-, and -A024-binding nanomeric epitopes in polyomavirus BK large T antigen," Human Immunology, vol. 70, no. 9, pp. 722728, 2009.

[62] B. Ramaswami, I. Popescu, C. Macedo et al., "The polyomavirus BK large T-antigen-derived peptide elicits an HLA-DR promiscuous and polyfunctional CD4+ T-cell response," Clinical and Vaccine Immunology, vol. 18, no. 5, pp. 815-824, 2011.

[63] A. Balduzzi, G. Lucchini, H. H. Hirsch et al., "Polyomavirus JC-targeted T-cell therapy for progressive multiple leukoencephalopathy in a hematopoietic cell transplantation recipient," Bone Marrow Transplantation, vol. 46, no. 7, pp. 987-992, 2011.

[64] S. Delbue, M. Ferraresso, L. Ghio et al., "A review of JC virus infection in kidney transplant recipients," Clinical and Developmental Immunology, vol. 2013, Article ID 926391, 2013.

[65] W. Caparrós-Wanderley, B. Clark, and B. E. Griffin, "Effect of dose and long-term storage on the immunogenicity of murine polyomavirus VP1 virus-like particles," Vaccine, vol. 22, no. 3-4, pp. 352-361, 2004.

[66] M. I. Husseiny and S. F. Lacey, "Development of infectious recombinant BK virus," Virus Research, vol. 161, no. 2, pp. 150161, 2011. 


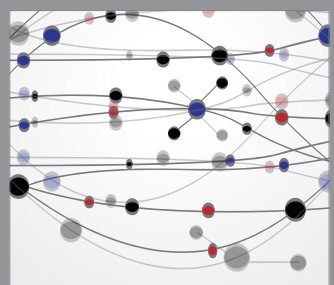

The Scientific World Journal
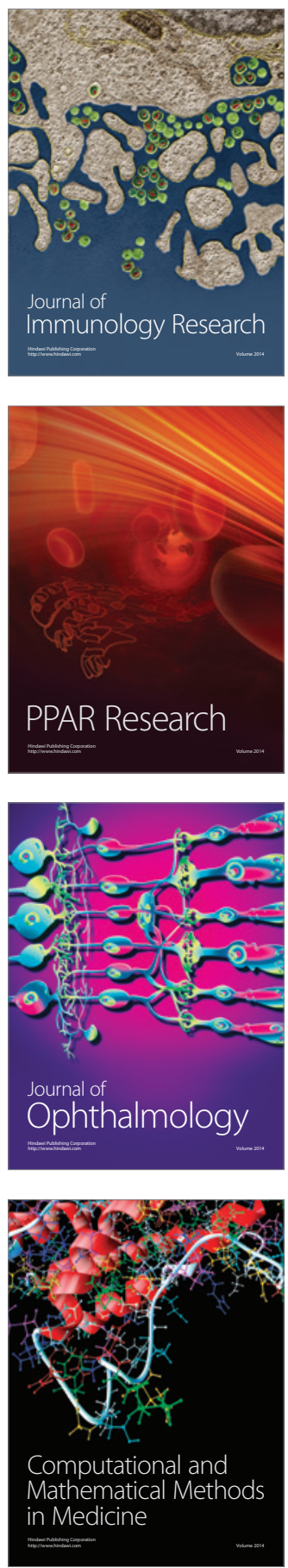

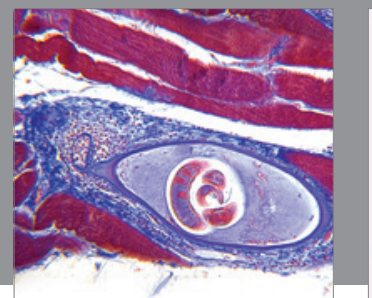

Gastroenterology

Research and Practice
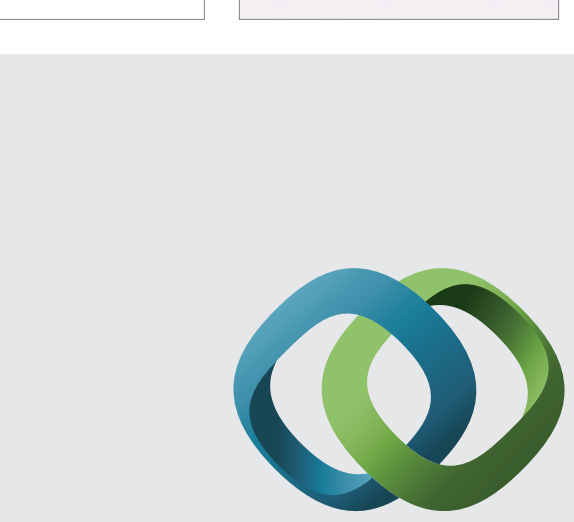

\section{Hindawi}

Submit your manuscripts at

http://www.hindawi.com
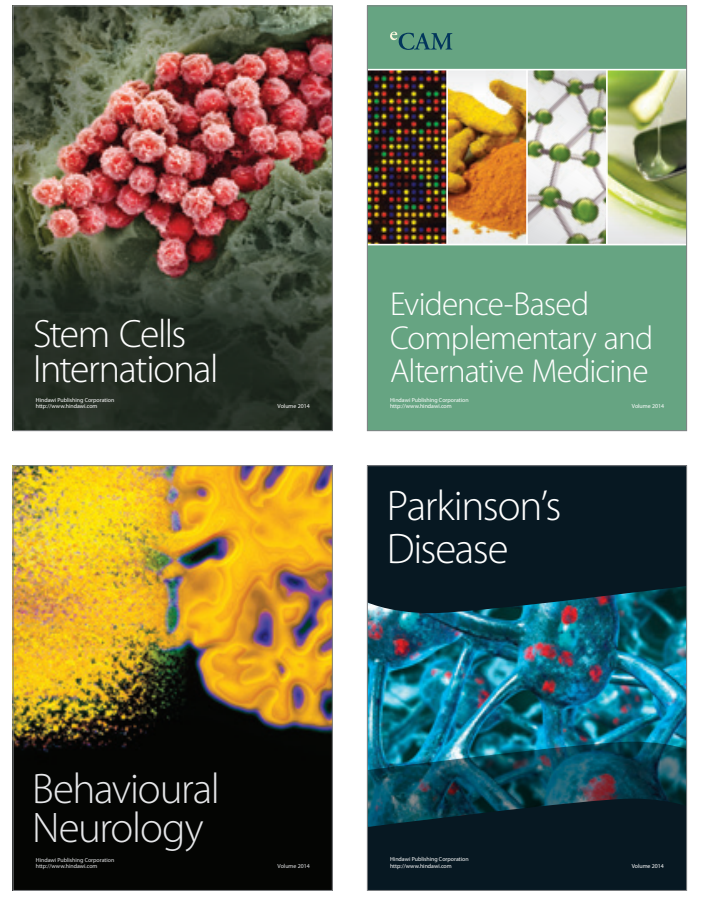
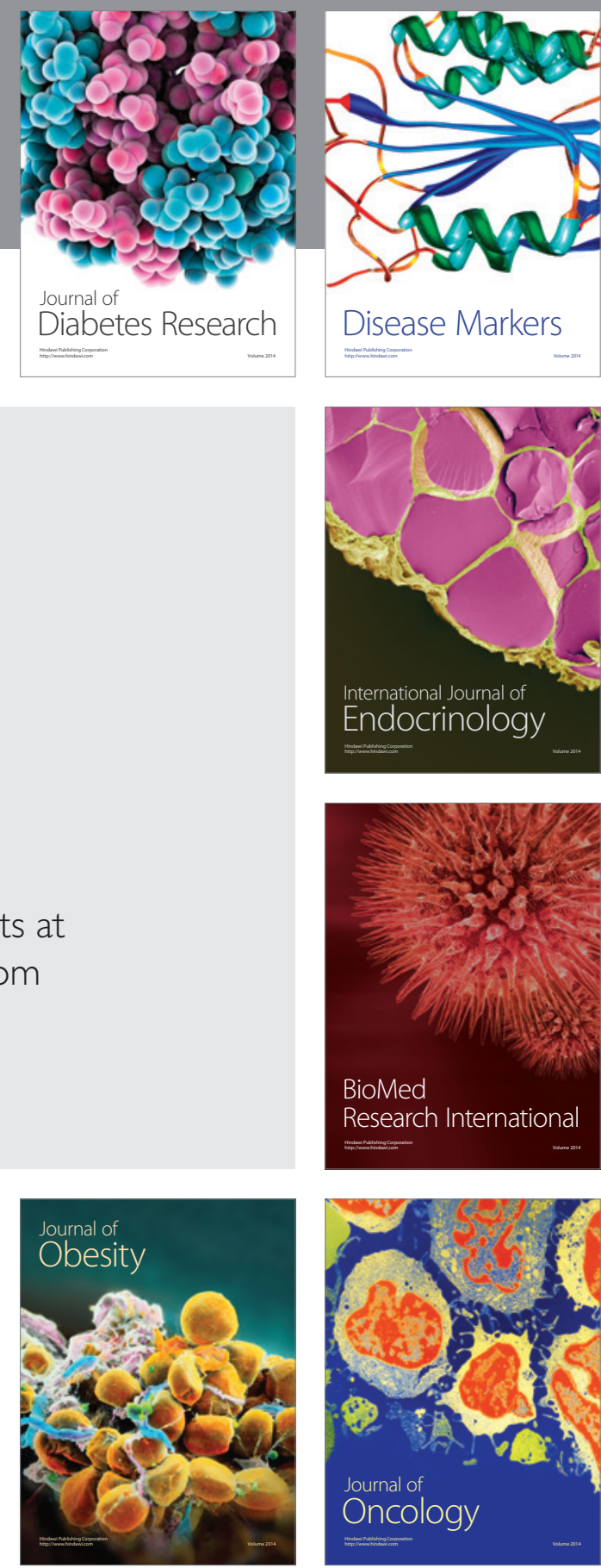

Disease Markers
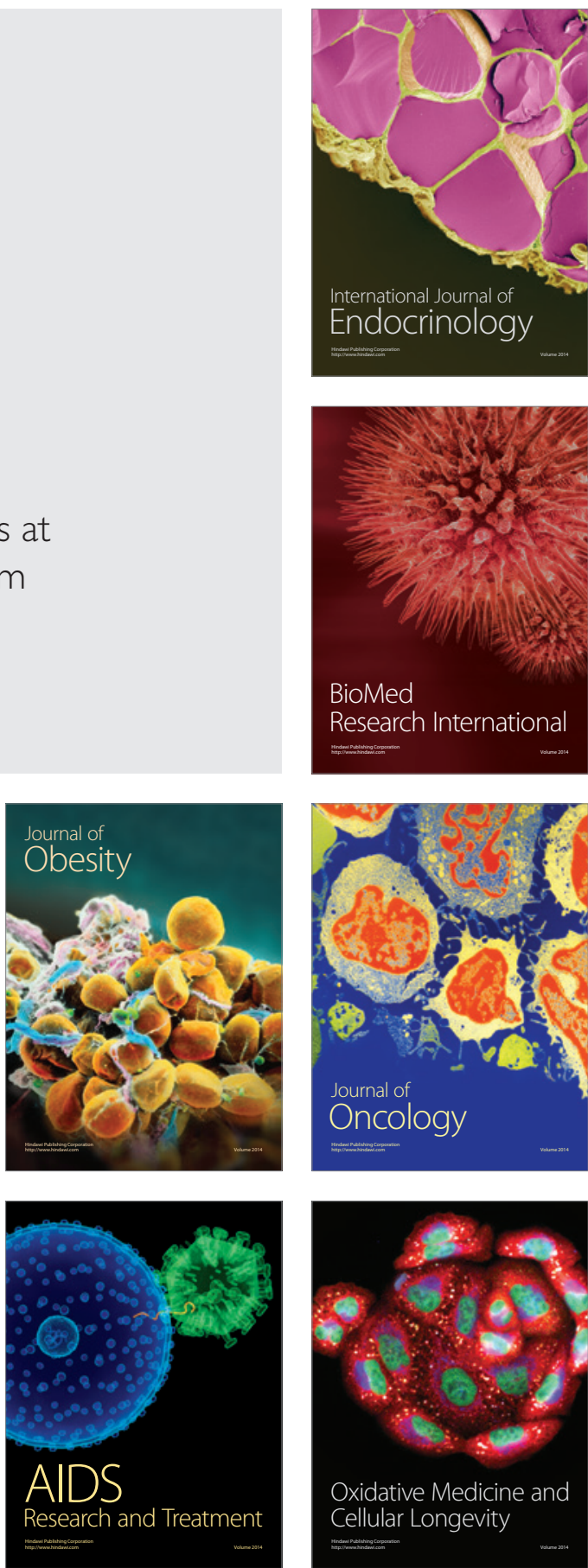